\title{
Numerical investigations regarding a novel process chain for the production of a hybrid bearing bushing
}

\author{
Bernd-Arno Behrens ${ }^{1} \cdot$ Hans Jürgen Maier ${ }^{2} \cdot$ Gerhard Poll $^{3} \cdot$ Peter Wriggers ${ }^{4} \cdot$ Fadi Aldakheel $^{4} \cdot$ Christian Klose $^{2}$. \\ Florian Nürnberger ${ }^{2}$. Florian Pape ${ }^{3}$. Christoph Böhm ${ }^{4} \cdot$ Anna Chugreeva $^{1} \cdot$ Timm Coors $^{3}$. Deniz Duran ${ }^{1}$. \\ Susanne E. Thürer ${ }^{2} \cdot$ Sebastian Herbst $^{2} \cdot$ Jae-II Hwang $^{3} \cdot$ Tim Matthias $^{1} \cdot$ Norman Heimes $^{1} \cdot$ Johanna Uhe ${ }^{1}$ (I)
}

Received: 15 May 2020 / Accepted: 20 October 2020 / Published online: 7 November 2020

(c) The Author(s) 2020

\begin{abstract}
This contribution deals with the numerical investigations to develop a novel process chain for hybrid solid components using Tailored Forming. For manufacturing a hybrid bearing bushing, co-extrusion is the first step to produce hybrid semifinished workpieces followed by a die forging process, machining processes and hardening. Combining aluminium with steel, compounds with wear-resistant functional surfaces and reduced weight are realised. Numerical simulations are a decisive part of the process chain design, for example to determine suitable process parameters for the co-extrusion process and to predict the thickness of intermetallic phases in the joining zone using a macroscopic phenomenological model. A numerical design including a tool analysis of the die forging process was carried out taking the experimentally determined material properties and the temperature profile after inductive heating into account. Additionally, the damage and fatigue behaviour of the polycrystalline material of the joining zone are modelled at the microstructure level. Moreover, a new discretization scheme, namely the virtual element method, which is more efficient at grain level, is developed regarding a crystal plasticity framework. Numerical simulations are used to develop inductive heating strategies for the forming process and for the design of the inductive hardening of the functional surface at the end of the process chain. In order to investigate the performance of this hybrid machine element under application-oriented conditions, a contact simulation is linked with a statistical damage model to calculate the bearing fatigue. In this study, a general overview of the individual process steps is given and results of the respective models are presented.
\end{abstract}

Keywords Tailored forming $\cdot$ Hybrid components $\cdot$ Finite element method $\cdot$ Virtual element method $\cdot$ Bulk metal forming $\cdot$ Intermetallic phases

\section{Introduction}

Johanna Uhe

uhe@ifum.uni-hannover.de

1 Institut Für Umformtechnik Und Umformmaschinen, Leibniz Universität Hannover, An der Universität 2, 30823 Garbsen, Germany

2 Institut Für Werkstoffkunde, Leibniz Universität Hannover, An der Universität 2, 30823 Garbsen, Germany

3 Institut Für Maschinenkonstruktion Und Tribologie, Leibniz Universität Hannover, An der Universität 1, 30823 Garbsen, Germany

4 Institut Für Kontinuumsmechanik, Leibniz Universität Hannover, An der Universität 1, 30823 Garbsen, Germany
The requirements for technical parts are steadily increasing due to, e.g. safety or environmental issues. This leads to the development of components with a compact design, low weight, and an enhanced functionality with respect to life-time. The use of mono-material components in the already established process chains is limited due to their specific material properties. Consequently, the product quality as well as its resource efficiency could be increased by combining different materials and thus, locally meeting the different mechanical demands of the components. The Collaborative Research Centre (CRC) 1153 of the Leibniz Universität Hannover is devoted to this topic. The overarching goal is the development of novel process chains for the production of hybrid solid components via Tailored Forming. 
Conventionally, for the production of hybrid components, the different materials are joined during forming or at the end of the manufacturing process. In contrast to this, the different materials are first joined and then formed according to the Tailored Forming approach. This allows to create novel joining zone geometries and to influence the microstructure by the thermomechanical treatment during the forming process. The design of the Tailored Forming process chain is accompanied by the numerical simulation of joining, forming and heat treatment processes as well as a durability analysis. The use of numerical calculation methods, such as the FEM, allows for a calculation of process variables in the conceptual and design phase. Thus, the number of cost and time-intensive experimental investigations can be reduced. For this reason, the development of numerical simulation models of the individual process steps is a main goal of the investigations of the CRC 1153. By this means, sufficiently accurate predictions about the production process and the component quality can be obtained. Therefore, it is particularly important to consider the material combination as well as the joining zone between the materials. For a realistic implementation of the numerical simulation of the process chains for the production of hybrid solid components, an extensive cooperation along the process chain as well as the transfer of calculation results and models is necessary.

Within the scope of this study, the numerical modelling of the different steps for the production of a hybrid bearing bushing via Tailored Forming as well as the linking between these steps is presented. In Fig. 1, the process steps which are investigated using numerical simulations of the manufacture of hybrid bearing bushings are shown.

The hybrid semi-finished workpieces are manufactured by co-extrusion of aluminium and steel and subsequently formed by die forging to a hybrid bearing bushing. The process parameters are determined by numerical simulations based on a previous material characterisation. Heating strategies for the die forging are calculated to define a process window with inhomogeneous temperature distribution, in order to achieve material-specific forming temperatures in both materials for sufficient forming behaviour. A subsequent heat treatment of the bearing bushing allows for the adjustment of locally adapted properties of aluminium and steel. Therefore, numerical simulations are also used for designing the hardening process. A damage and failure prediction of the joining zone of the produced hybrid solid components as well as the rolling contact fatigue are also obtained via numerical modelling.

\section{State of the art}

The semi-finished workpieces for the hybrid bearing bushes are manufactured by co-extrusion. Actual local values and their influence on the properties of the final part like temperature or contact pressure in the welding chamber are difficult to obtain and sometimes experimentally not measurable during the process. Hence, the use of FEM can reduce cost and resource extensive investigations. Due to this fact, FEM has been widely used to simulate the extrusion process of aluminium alloy profiles [1]. In recent years, there have been a number of studies on co-extrusion processes using FEM to comprehend the observations made during extrusion experiments. In most cases, the investigations focus on thin reinforcing elements like steel wires, which are fed to the extrusion process from outside into the deformation zone [2] or hybrid extrusion billets [3]. While there have been a number of studies regarding the bonding strength of co-extruded profiles. There are only a few studies on the formation of intermetallic phases during the co-extrusion process. For example, Kittner used Fick's law to predict the depth of the intermetallic phase seam for the co-extrusion of aluminium-magnesium compounds [4].

For forming of previously joined workpieces to final geometry of hybrid bearing bushings, a die forging process is implemented. Modelling of forming processes by FEM can predict material flow and material distribution in the whole part as well as in the interface zone. Misirli et al. carried out an experimental and analytical study on upsetting of cylindrical parts with copper or brass core and steel on the outer diameter at ambient temperature and with varying

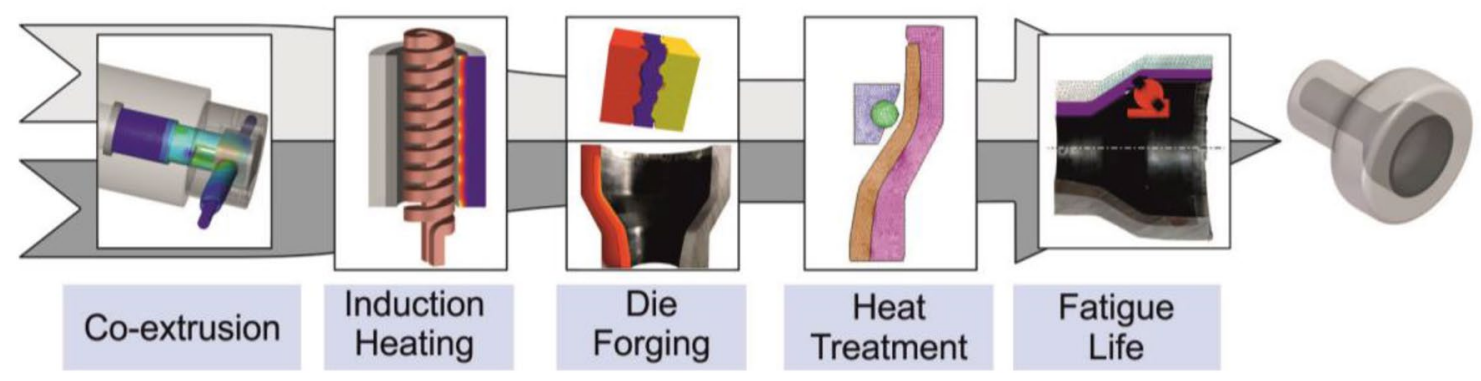

Fig. 1 Schematic illustration of the procedure for the numerical modelling of the process chain for the production of a hybrid bearing bushing 
height reduction [5]. It was established that material flow has an inhomogeneity because of different flow stresses and increasing height reduction leads to defects in the interface zone (e.g. cavities) and failure in the outer steel part. In study of Politis et al., the effect of tooling and interfacial friction on the material flow behaviour during forming of bi-metal gears was investigated by numerical simulation and experiments [6]. For this approach, different tooth ring thicknesses and different material combinations, such as steel-aluminium, steel-lead, steel-copper and copper-lead, were investigated. It was found that increasing friction between the forming tooling and the workpiece lead to an axial lock of the ring material. The initial thickness of the outer ring is crucial in order to prevent failure. The forgeability of prejoined cladded workpieces made of two different steels was investigated in the research work of Wang et al. [7]. The experimental upsetting tests showed a specific crack type as result of global mechanical interaction between materials. The occurrence and position of the cracks could be predicted by FEM using a Latham and Cockcroft criterion.

When addressing the occurrence of these cracks within a numerical framework, investigations at lower length scales are needed in order to describe physical effects which lead to macroscopic accumulation of these cracks [8]. By facing a microstructural framework, one models at level of grains in metallic materials, respectively. Since growth of cracks is induced by accumulation of micro-voids, this process is induced within plastic regime. In this regard, a viscous crystal plasticity formulation is utilized in this contribution [9]. Moreover, the virtual element method (VEM) [10] is employed towards this framework to account for a robust and efficient computational environment at grain-level. To obtain effective quantities on macrostructure, a homogenization technique is implemented in the constitutive framework.

After the forming process, the functional surface of the steel component that acts as the outer bearing ring needs to be hardened. Since the austenitisation temperatures are well above the solidus temperature of the aluminium alloy, only a local hardening can be applied that additionally features a sufficiently high power transmission density. Hence, induction hardening was chosen. While the numerical simulation of the induction heating and the phase transformations are state of the art (e.g. [11]), analyses of the process design with regard to an adjacent aluminium component are not known from literature. However, the authors investigated the influence of aluminium parts adjacent to steel surfaces that are to be induction hardened for simple geometries. A high correlation between calculated and measured induction hardening results could be achieved in [12].

The fatigue life of components subjected to rolling contact stress depends on their surface and boundary zone properties [13]. Changes here, in particular the presence of different materials, can therefore be potentially sensitive to the service life. Few studies are known from the literature that have investigated the fatigue behaviour of multi-material rolling bearing components. Hetzner described as an outlook that bearings with a core made of one alloy and a raceway made of a different alloy applied by laser cladding could increase the bearing life [14]. However, the process is not state of the art. So far publications have mostly been found in the field of process development, for example [15]. Parts of the authors have investigated steel-steel components produced by tailored forming. Aluminium-steel components have not been investigated so far, besides [16, 17].

\section{Numerical modelling of the lateral angular co-extrusion of aluminium and steel}

As the initial step of the Tailored Forming process chain, the different materials are joined by co-extrusion. For the numerical investigations of the co-extrusion process, the commercial FE analysis system Forge NxT 2.1 with an implicite solver was used. The FE model for the co-extrusion via Lateral Angular Co-Extrusion (LACE) is shown in Fig. 2a. The tool enables the co-extrusion of the aluminium alloy EN AW-6082 at an angle of $90^{\circ}$ between the punch direction and the exit port of the profile. This allows for a continuous feed of the steel rods consisting of $20 \mathrm{MnCr} 5$ (AISI 5120) into the welding chamber. The process results in coaxial profiles of a steel rod, embedded in an aluminium matrix. Due to the separation of the aluminium flow in the tool body, two longitudinal weld seams are formed during the LACE process. With a diameter of $55 \mathrm{~mm}$ for the aluminium billet, $15.2 \mathrm{~mm}$ for the steel rod and an opening diameter of $28 \mathrm{~mm}$ for the die, the extrusion ratio equals to $\psi$ of 6:1. The compound profiles were extruded at a ram speed of $0.5 \mathrm{~mm} / \mathrm{s}, 2 \mathrm{~mm} / \mathrm{s}$ as well as $4 \mathrm{~mm} / \mathrm{s}$ on a $2.5 \mathrm{MN}$ laboratory extrusion press (Müller Engineering). The tool design and the detailed experimental procedure for a ram speed of $0.5 \mathrm{~mm} / \mathrm{s}$ are described in [18]. The tools and the extrusion billet were preheated to $500{ }^{\circ} \mathrm{C}$ and the temperature of the steel rod equalled the room temperature at the beginning of the experiment.

The tools were modelled as rigid bodies in the FE simulations to reduce the computing time. The flow behaviour of the billet material was defined using flow curves, which were determined by upsetting experiments under process relevant temperature conditions. The time step value was set to $0.03 \mathrm{~s}$, resulting in 3300 time steps in total. Tetrahedronal volume elements of a linear interpolation type, which are typical for metal forming simulations were used with a minimum element edge length of $0.28 \mathrm{~mm}$. The influence of the minimal element edge length on the accuracy of the predicted extrusion force and computation time 


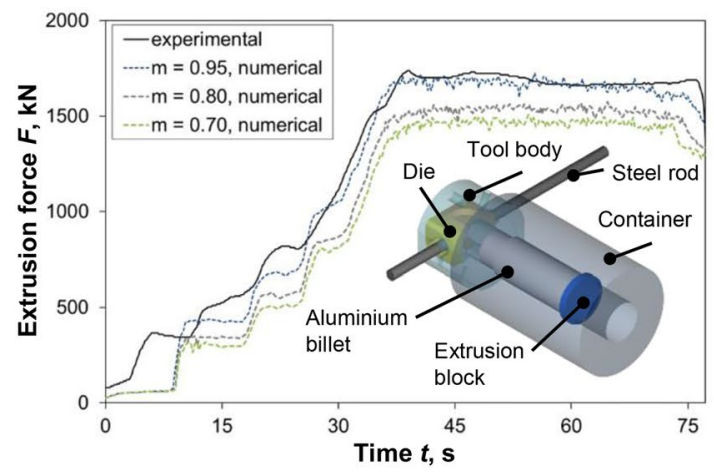

(a)

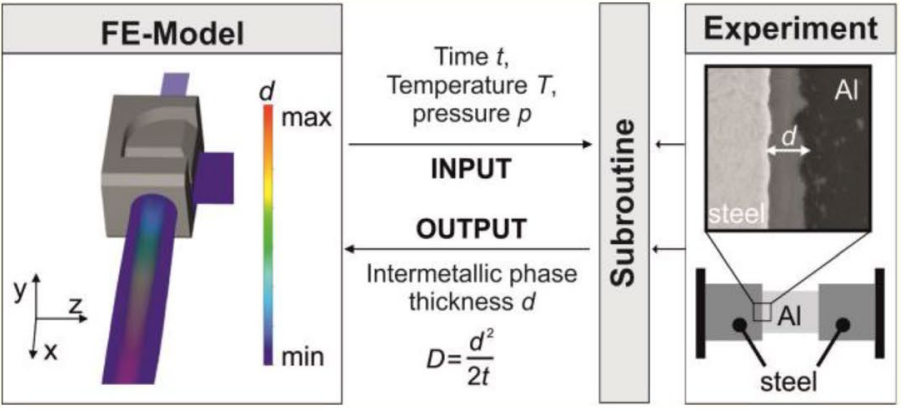

(b)

Fig. 2 a Comparison between the predicted and measured force-time curves and FE-model set-up [18], b Implementation of the phenomenological model in the FE simulation

were investigated and described in a previous work by the authors [18]. A periodic initiated remeshing criterion and an automatic size criterion were used for remeshing due to the intensive plastic deformation during the redirection and extrusion within the LACE process. Due to this, remeshing followed a fixed incremental step of 20 steps. Automatic size criterion is used to refine the mesh of the workpiece according to the curvature of the die in the contact area. In order to ensure that at least five elements were present along the thickness of the aluminium part in the area of profile exit, a refinement box was employed. For the description of the frictional behaviour between the billet and the tool, Tresca's friction model was used according to literature [19]. For a parametric study, friction factors of $0.7,0.8$ and 0.95 between the billet and the tool were chosen. As shown in Fig. 2a a good correlation between the predicted extrusion force for a friction factor of 0.95 and the measured extrusion forces was achieved. The differences between the predicted and measured force-time curves in the beginning are caused by the neglected elastic deformation of the tooling in the numerical simulation as well as the variation of the ram speed in the experimental investigations due to a higher ram speed during the filling of the tool. In addition, a good agreement between the measured and calculated temperature curves of the steel rod is presented in [18].

As intermetallic phases have a strong impact on the mechanical properties and the quality of the aluminium-steel joint, experimental investigations are carried out on a quenching dilatometer DIL 805A/D + T (TA Instruments) in order to determine the influence of the process parameters like temperature and pressure on the development of intermetallic phases in the joining zone. To determine the parameters for these experiments, numerical simulations with different extrusion parameters such as ram speed, temperature, and extrusion ratio were carried out to determine their influence on the material flow and the particular temperature, contact pressure, and contact time between aluminium and steel. Based on the data of the metallographically measured thickness of intermetallic phases in the dilatometer experiments, a macroscopic phenomenological model is developed based on the Einstein-Smoluchowski equation (see Fig. 2b). The thickness of the intermetallic phases $d$ for the co-extrusion of aluminium-steel compounds in LACE is calculated based on the experimentally determined diffusion coefficient $D$ and the forming time $t$. A detailed overview and first verification of the subroutine is given in [20].

The development of the phenomenological model takes place in constant cooperation and consultation with the results of the microscopic simulation of the joining zone. For example, the experimentally and numerically determined phase seam thicknesses are used as input variables for the modelling and simulation of the joining zone on the microscale and macroscale during deformation.

\section{Heating strategies for the forming process}

For achieving sufficient formability, the individual material in the hybrid workpieces needs to be heated to its materialspecific forming temperature. In the case of the previously joined workpieces, heating can be implemented by induction heating, where the heating process can be targeted tailored using the skin effect [21]. The intention is to generate an inhomogeneous temperature gradient in the workpiece to obtain a relatively similar flow behaviour of the two dissimilar materials, aluminium and steel, during the forging process. It is a challenging task due to distinct thermo-physical and thermo-magnetic properties of the used materials. Since the forming temperature of steel significantly exceeds the melting point of aluminium, it is necessary to prevent local melting of the aluminium alloy at the joining interface. 
Induction heating simulations (magnetodynamic-thermal coupled analyses) were conducted using Marc Mentat (MSC Software), a general purpose FE analysis software. Due to the axisymmetric semi-finished workpiece, the model was reduced to two dimensions. The hybrid workpiece, the inductor with ten windings as well as the air surrounding these components were modelled and the required material properties were accordingly assigned as a function of temperature. Ideal thermal contact was assumed between the aluminium alloy and steel.

Simulation results for two illustrative case studies are presented below. In the first case, strategy (a), the coil is loaded with $750 \mathrm{~A}$ at an operating frequency of $50 \mathrm{kHz}$. In the second case, strategy (b), the applied current and the operating frequency are increased to $1000 \mathrm{~A}$ and $75 \mathrm{kHz}$, respectively. The temperature distributions in the bi-material workpieces after a certain heating time are shown in Fig. 3 [22]. In both strategies, temperature gradients in the steel were observed showing a decreasing trend from the inner surface to the joining interface, as anticipated due to the skin effect. On the contrary, the aluminium is not affected by the eddy currents occurring in the alternating magnetic field. The aluminium temperatures increase up to $350{ }^{\circ} \mathrm{C}$ for strategy (a) and $200{ }^{\circ} \mathrm{C}$ for strategy (b) as result of heat conduction from steel. The homogeneous temperature distribution in the aluminium part is attributed to approximately four times higher thermal conductivity of aluminium compared to steel [23].

The transfer time of $2 \mathrm{~s}$ is taken into account in the process design, as the heat will keep dissipating from steel to aluminium alloy during the transfer. For this time, a relaxation step without heat input was added subsequent to the heating step with the maximal generator power. Temperature

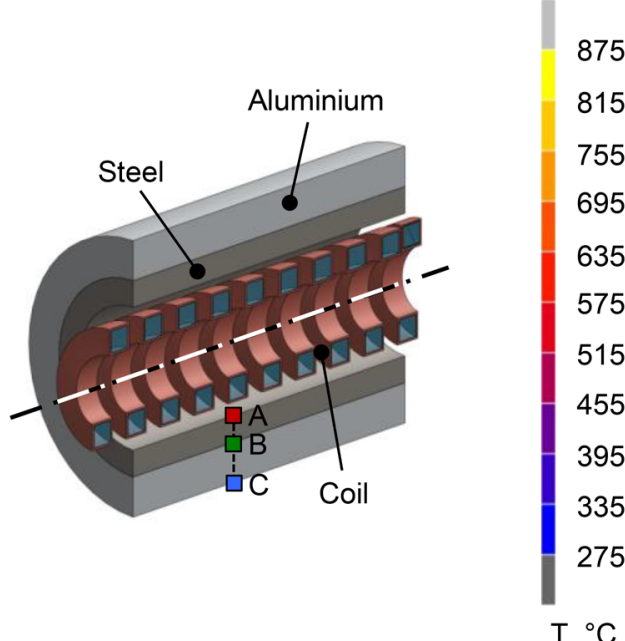

Fig. 3 Temperature distributions in the hybrid workpieces [22]

\section{Heating Strategy (a)}

Heating Time $15 \mathrm{~s} ; 750$ A (Frequency $50 \mathrm{kHz}$ )

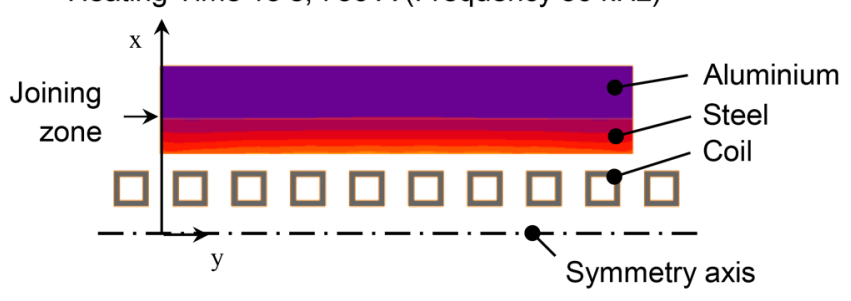

Heating Strategy (b)

Heating Time $5 \mathrm{~s} ; 1000$ A (Frequency $75 \mathrm{kHz}$ )

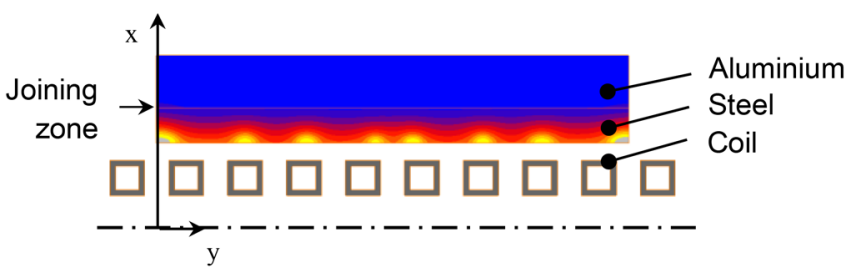

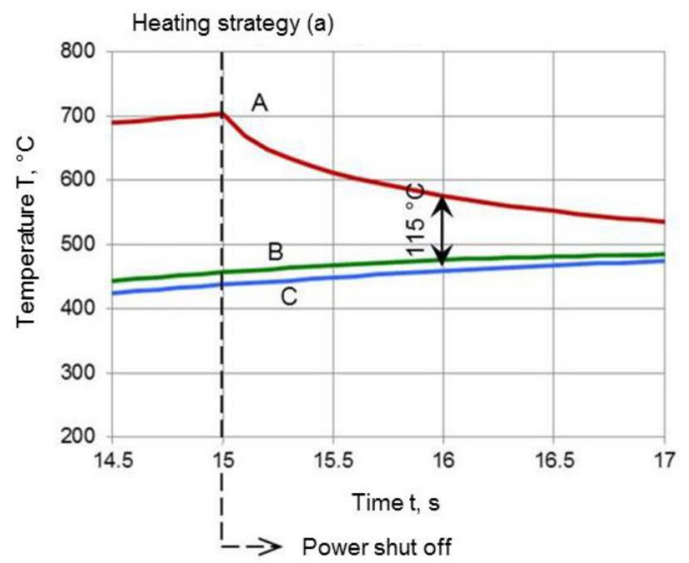

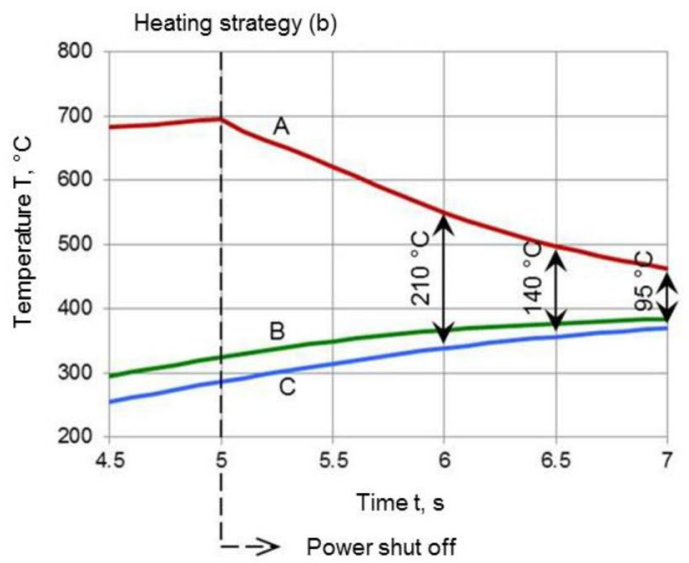

Fig. 4 Progression of temperatures after induction heating [22] 
histories of three distinctive points marked in the Fig. 3 were given in Fig. 4 [22]. Point A is on the inner diameter (steel), point $\mathrm{B}$ is on the joining line and point $\mathrm{C}$ is on the outer diameter (aluminium alloy).

A temperature difference of $266^{\circ} \mathrm{C}$ is observed between the inner and outer diameter in strategy (a). Strategy (b) leads to a difference of $408{ }^{\circ} \mathrm{C}$, which is regarding to the $\mathrm{FE}$ results mainly dominated by the higher current amplitude. Thus, the strategy (b) with a higher current transmission and operating frequencies allows shorter heating time and higher temperature gradients. Therefore, it appears to be more favourable for the investigated heating process. Nevertheless, temperature gradients diminish in a short span of time, which makes it essential to find further means for a better temperature control. To address this need, modified concepts with a simultaneous cooling will be applied. The main focus is to force convection on the workpiece's outer surface during the heating process (e.g. local spray cooling or internally cooled gripper jaw). Correct representation of the temperature distribution within the hybrid semi-finished component is essential in order to predict the individual materials' flow accurately. The temperature field calculated by induction heating simulation will be transferred to the forming simulation and used as initial temperature input. The details of the forming simulation are explained in the next section.

\section{Prediction of process parameters for the die forging}

The commercial FE-system simufact.forming 14.0 was used to model the forming process based on material data from performed experiments. For this purpose, a simplified form of semi-finished hybrid components without consideration of the joining zone is assumed initially. Since the heating as well as the part and tool geometry are axially symmetrical, the simulation was performed in 2D (element type Quad10). The semi-finished product was modelled with about 4600 elements (aluminium side) and 1000 elements (steel side). Moreover, the effects of heat transfer between different materials of the hybrid semi-finished components evaluated during the previous step will be used as thermal boundary conditions. The experimentally determined temperature distribution was mapped to the semi-finished product geometry using a subroutine. An ideal thermal contact was used between the aluminium alloy and steel used during the forming process. Utilising the forming simulation the forming force, the material flow as well as the tool stress behaviour can be captured accurately. This helps to avoid manufacturing errors such as folds. For the design of the tools, an automatic time step value was used to plot the forming results for each millimeter of forming stroke, resulting in 1550 increments. The total forming stroke is $78 \mathrm{~mm}$.

A coupled numerical investigation approach was considered for the die stress analysis. The tools were modelled as elastically deformable bodies whereas the workpieces were designed as plastically deformable. The FE model shown in Fig. 5a was used for the design of the die forging process. In order to ensure the forming of the inner contour of the bearing bush during the forming process, the tool system was designed with a punch and a punch guide, which are located inside the hybrid hollow semi-finished product during the forming process. The closing plate was equipped with disc springs to allow for easier separation of the upper tool from the finished forged part. This design concept also compensates for possible deviations in the volume of the semi-finished product. The results of this investigation provide an overview about the occurring loads and stresses on the dies and enable an efficient tool design. In addition to the FE model in for the production of the bearing bush in Fig. 5a, the results of the tool stress analysis for the upper and lower tool are shown. To compare and assess the process loads, the first principal stress, which is an indicator of crack initiation, as well as the von Mises stress, which indicates regions of plastic deformations, is taken into account. The maximum loads occurring during the forging are found to be lower than the yield stress of $1400 \mathrm{MPa}$ of the tool steel X37CrMoV5-1 (AISI H11) [24].

The initial temperature distribution of the semi-finished product after heating shown in Fig. 3 was transferred to the meshing data of the forming process. In Fig. $5 b$ the von Mises stress distribution in the forged hybrid bearing bushing and the resulting material flow and temperature distribution after forming are compared to a forged bearing bushing.

Due to the lower yield stress of aluminium, it passes over the steel during the forming process and forms an undercut in the upper part of the bearing bushing. The outer contour of the bearing bushing, the undercut in the upper part area and the determined course of the joining zone show a qualitatively good agreement between experimental and numerical results. The geometry of the forged component i.e. the thickness of aluminium as well steel region were transferred to subsequent heat treatment simulation.

\section{Modelling and simulation of the joining zone}

Damage in metallic solids is induced in a microstructural environment due to micro-voids and their accumulation during loading states [8]. Hence, in case of a physics-based modelling of processes with high deformations and loading states like forming, the numerical framework has to consider also microstructural effects. While macrostructural 


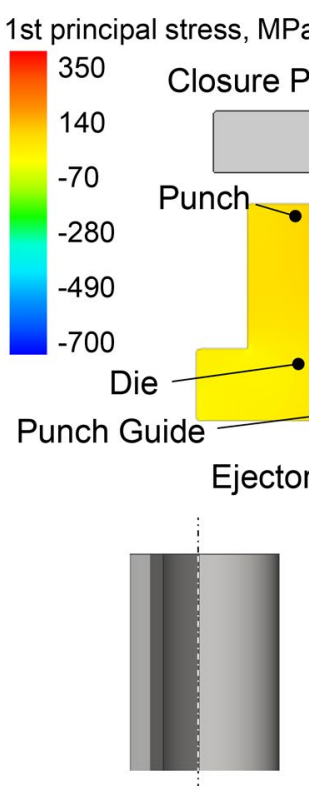

Stroke: $0 \mathrm{~mm}$
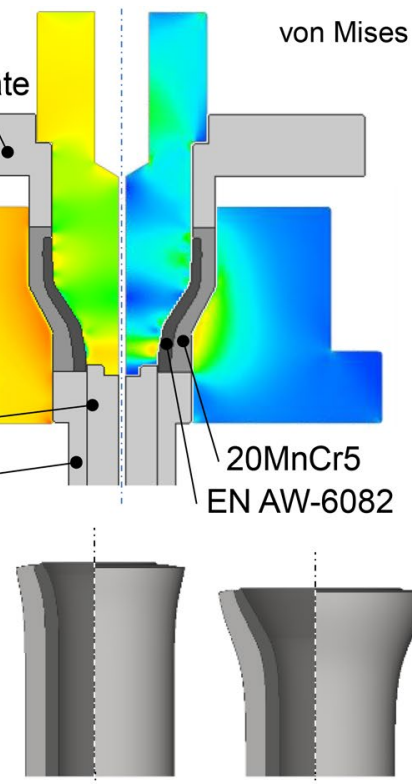

$25 \mathrm{~mm}$

(a)

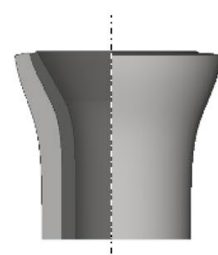

$50 \mathrm{~mm}$
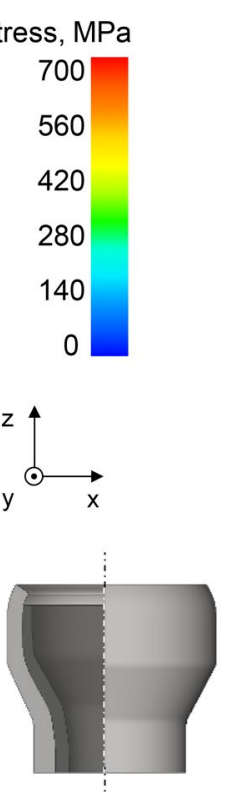

$75 \mathrm{~mm}$

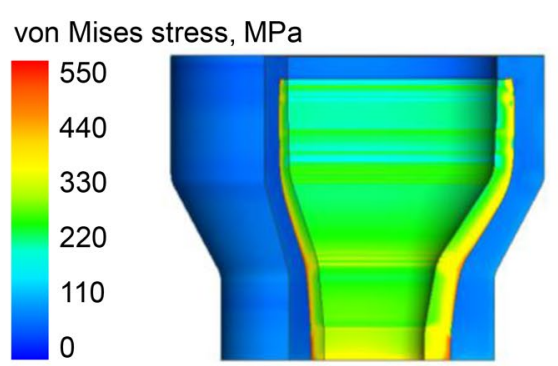

Temperature, ${ }^{\circ} \mathrm{C}$
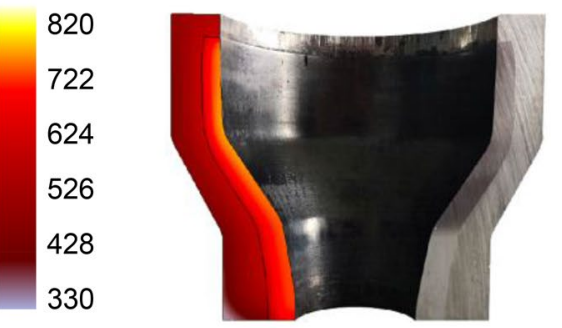

(b)

Fig. 5 a FE model and the results of the die stress analysis of the forging process for the upper as well as the lower die; $\mathbf{b}$ the von Mises stress of the hybrid bearing bushing as well as the resulting material flow and temperature distribution after forming

properties are often assumed to behave isotropic as well as of homogeneous distribution, its microscopic counterpart is made out of grains and demonstrates anisotropic response. Therefore, the modelling of these heterogeneous and complex geometric properties, by using the well-known theory of representative volume elements (RVE), is achieved by a voronoi tessellation, see Fig. 6a.

Moreover, cubic material symmetry is discovered through the natural arrangement of the atoms in the crystal lattice at metallic materials such like steel and aluminium [25]. By specifying the RVE to be located at the joining zone of a bearing bush, grains of both type of materials appear. As a consequence, the physical model has to consider both types of crystal lattices, which are either body centred cubic (bcc) or face centred cubic (fcc) structured. In that microscopic environment, constitutive models are embedded within the framework of crystal plasticity $[9,26]$. Here, remanent deformations such as applied in forming processes regarding to tailored forming process chain, are induced by plastic slip of atomic layers against each other. Consequently, these slips

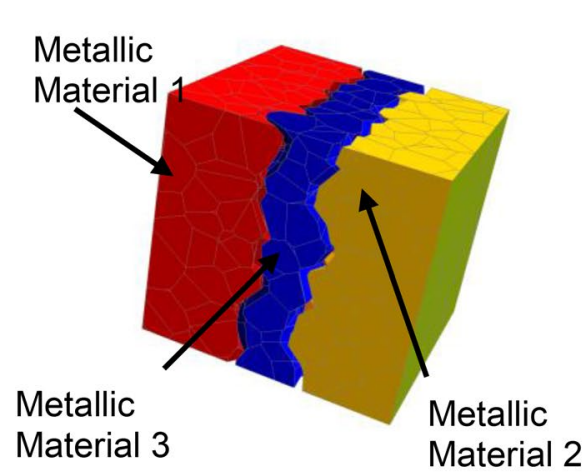

(a)

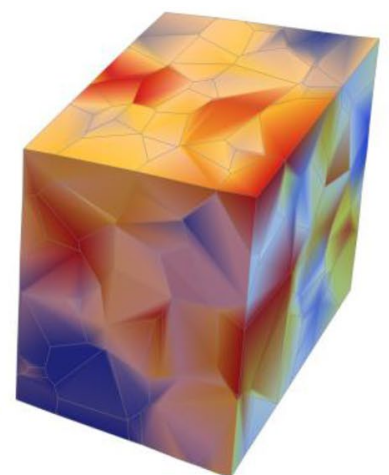

(b)

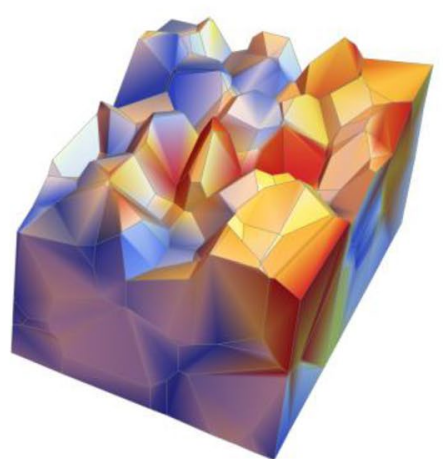

(c)
Fig. 6 a Artificially generated representative volume element (RVE) of a joining zone, consisting of three different materials, distribution of $\mathbf{b} \dot{\gamma}_{1}$ acting on slip plane (lllll 111 ) of a fcc lattice; $\mathbf{c}$ equivalent von
Mises stress; in a RVE with polycrystalline structure, computed in a virtual element environment 
resulting from global loading on the structure. This loading is mapped through the Schmid tensor $\boldsymbol{m}_{\boldsymbol{\alpha}}=\boldsymbol{d}_{\alpha} \otimes \boldsymbol{n}_{\alpha}$ onto the particular slip system $\alpha$, identified by its slip direction $\boldsymbol{d}_{\alpha}$ and slip normal $\boldsymbol{n}_{\alpha}$, respectively [9]. Furthermore, the slip is controlled by the resolved shear stress

$\tau_{\mathrm{S}}^{\alpha}=\sigma: m_{\alpha}$,

that defines a threshold as a slip resistance for activation of slip on particular slip system [26]. However, to overcome the costly search for active set of slip systems by algorithmic treatment in local routines, a visco-elastic-plastic approach is employed in this contribution, see [25, 26]. Therefore, the angle of shear in a crystal lattice of slip system $\gamma_{\alpha}$ is introduced as a suitable measure for plastic deformation in terms of shear, acting on that system. The map of plastic deformation, introduced by the evolution law $[9,26]$

$\boldsymbol{L}_{p}=\dot{\boldsymbol{F}}_{p} \boldsymbol{F}_{p}^{-1}=\sum_{\alpha} \dot{\gamma}_{\alpha}\left(\boldsymbol{D}_{\alpha} \otimes \boldsymbol{N}_{\alpha}\right)$,

yields to a first order ordinary differential equation of tensorial type for update of plastic deformation. Here, $\dot{\gamma}_{\alpha} D_{\alpha}, N_{\alpha}$ are the slip direction and unit normal of the slip system in reference configuration, respectively. The shear rate $\dot{\gamma}_{\alpha}$ is computed through a power law of phenomenological type [25]. This framework covers the underlying physics of forming processes of metallic structures as well as it states an appropriate starting point regarding investigations on damage and fatigue of cyclic loadings due to their appearance in working areas of hybrid bearing bushes.

However, since microstructural framework is addressed in this contribution, a question regarding suitable discretisation schemes, in line with robust and efficient performance at heterogeneous environment, arises. Here, the recent developed virtual element method (VEM) has shown the ability to combine these requirements combined with the ability of matching arbitrary shaped geometric structures [10].

Thus, the underlying grain-structure is fitted by the polyhedral character of each virtual element. As a consequence, either a faster computation or the consideration of higher numbers of grains by widening the RVE at same computational cost is achieved. Figure $6 \mathrm{~b}, \mathrm{c}$ demonstrates the result of a computation at fcc lattice structure with underlying material data from that bearing bush in aluminium regime, performed in virtual element environment, on a particular slip system.

Afterwards the obtained results are made available at macroscopic length scale through applicable homogenization strategies such as a classical volume averaging approach [25]. However, by means of the demanding cost of computational time in a two-scale framework, considering plastic local routines, this strategy has to be adapted through adaptive methods as for instance a supported machine learning schemes. The framework in this contribution takes place in the design process of tailored forming process chain, as well as a partial support within numerical lifetime approaches on the bearing bush. Information is shared from other subprojects regarding material data from experimental observations and numerical fitting to those, for instance at its application within phenomenological lifetime predictions. Moreover, the framework is therefore adapted through an interface to be implementable into recent works of other parts in the process chain, also located in either design-related fields as well as to material sciences for an appropriate fitting to experimental observations under realistic loading states. The link to former and following steps in the process chain (sketched in Fig. 1) is achieved by the exchange of material- as well as process-parameters, which represent the input data for the numerical simulations. The interaction with other process steps is based on effective parameters (homogenization procedure), i.e. averaged constitutive matrices or resulting loads, as input or feedback.

\section{Modelling of the induction hardening of the hybrid bearing bushing}

To obtain a wear-resistant surface in the contact area to the balls of the bearing, a local martensitic surface hardening has to be carried out. In the process chain, this is done by employing induction heating and air-water spray quenching after the forging process. Subsequently, a precision turning needs to be carried out prior to testing or the intended use.

The heat treatment including the phase transformations in the steel component was modelled in the FEM software DEFORM ${ }^{\mathrm{TM}}$-2D employing rotational symmetry. DEFORM ${ }^{\mathrm{TM}}$ offers modules for heat transfer (e.g. for quenching), phase transformations and induction heating. This 2D geometry of the forming simulation including the material distribution was meshed and employed for the heat treatment simulations. Thus, resulting geometry and material distribution from forging step is taken into account. A single winded copper coil (material data from DEFORMLibrary), in combination with an iteratively designed field former (Fluxtrol 50, data taken from manufacturer's specifications) were placed close to the future contact surface. The meshed model is depicted in Fig. 7a. For the $20 \mathrm{MnCr} 5$ steel (AISI 5120), thermo-physical and transformation material data was exported from the materials properties calculation software JMatPro ${ }^{\circledR}$ for the five possible microstructural constituents austenite, ferrite, pearlite, bainite and martensite. The deformation behaviour was implemented via measured flow curves (see chapter "Numerical modelling of the lateral angular co-extrusion of aluminium and steel") and the electromagnetic properties were adapted from [27]. For the aluminium billet (EN AW-6082), the 
(a)

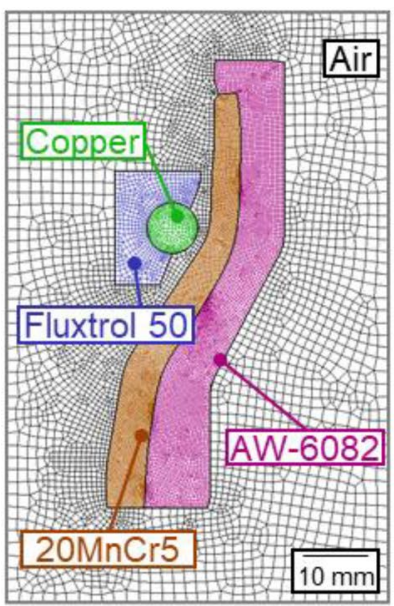

(b)

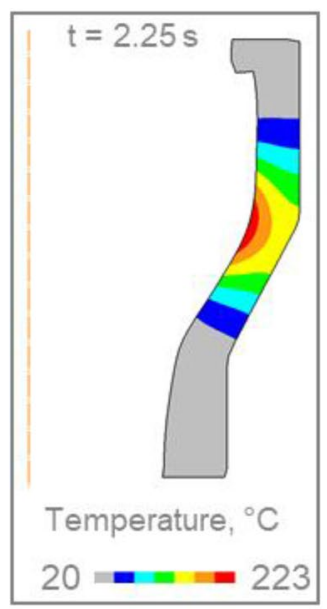

(c)

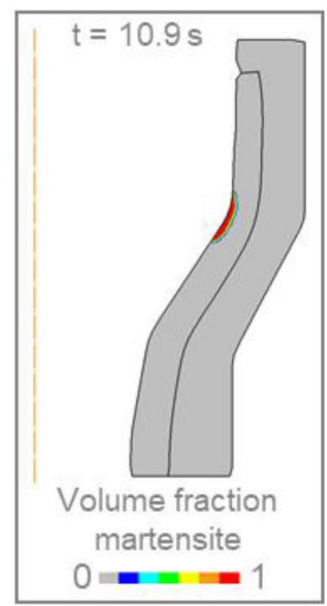

Fig. 7 a Meshed model, b temperature distribution at peak maximum temperature in the aluminium, $\mathbf{c}$ volume fraction of martensite after quenching for an assumed intermetallic phase layer thickness of $0.25 \mu \mathrm{m}$

material data was taken from the material library featured in DEFORM. Sticking condition was defined between the steel and aluminium to model the intermetallic joint. The heat transfer coefficient between the two materials was set to $40 \mathrm{MW} \mathrm{m}{ }^{-2} \mathrm{~K}^{-1}$, assuming an intermetallic phase layer thickness of approximately $0.25 \mu \mathrm{m}$ and an average heat conductivity of the intermetallic phases of $10 \mathrm{~W} \mathrm{~m}^{-1} \mathrm{~K}^{-1}$ [28]. As shown in Herbst et al., the IMP layer thickness can be adjusted by choosing the T6-treatment conditions carefully [29]. This treatment is essential after the hot forming operation and the resulting thicker intermetallic phase layer works as an insulation layer. Hence, the simulation was also carried out assuming a layer-thickness of $2 \mu \mathrm{m}$, which was found to be the maximum layer-thickness that results in an acceptable bond strength [29]. This layer-thickness results in a heat transfer coefficient between steel and aluminium of $5 \mathrm{MW} \mathrm{m}^{-2} \mathrm{~K}^{-1}$.

The heating was modelled by defining a constant electrical input power at the coil of $90 \mathrm{~kW}$ with a frequency of $115 \mathrm{kHz}$ in the induction heating module of the FEM software and an electrical to thermal power conversion ratio of $60 \%$ to account for the complex conjugate matching. A heating time of $0.9 \mathrm{~s}$ with a time step duration of $0.002 \mathrm{~s}$ was simulated. Subsequently, the cooling by air water spray cooling was simulated for $10 \mathrm{~s}$ with a time step duration of $0.01 \mathrm{~s}$ by employing experimentally determined heat transfer coefficients on the inner surface of the bearing.

After the $0.9 \mathrm{~s}$ of heating, a maximum temperature of $1060{ }^{\circ} \mathrm{C}$ is calculated at the inner surface of the steel component for both assumed intermetallic phase layer thicknesses. After the $10 \mathrm{~s}$ of quenching, the maximum temperature in the shaft is reduced to below $90{ }^{\circ} \mathrm{C}$. No significant difference $(<2 \mathrm{~K})$ of the peak temperature in the component as well as in the maximum temperature of the aluminium part was observed when the layer-thickness was varied. Hence, further analyses were carried out just for the intermetallic phase layer-thickness with the highest resulting heat transfer coefficient $(0.25 \mu \mathrm{m})$ as this would be the most critical case in terms of aluminium temperature. In Fig. 7b, the temperature distribution at the time of the maximum temperature in the aluminium part is depicted. The maximum temperature is well below the solidus temperature of the alloy. The volume fraction of martensite after the quenching operation is depicted in Fig. 7c. The future contact area to the rolling element is fully martensitic and the depth, to which martensite was formed is around $1.4 \mathrm{~mm}$.

Verification experiments will be subject of future work. However, from previous work of the authors it is already known that the parameters employed in the present simulation lead to a good agreement between calculated and measured time-temperature trends and martensite distributions in a similar task. There, axially joined aluminium-steel hybrid shafts were induction hardened [12].

\section{Fatigue lifetime model for a hybrid bearing bushing under rolling contact load}

In order to estimate the performance of the finished Tailored Forming-bearing, a fatigue life evaluation is carried out. The hybrid bearing bushing represents the outer ring of an angular contact ball bearing. Lifetime of a rolling bearing is defined as the number of bearing revolutions from which the first damage due to material fatigue occurs. Rolling contact fatigue (RCF) leads to bearing failure even under ideal lubrication conditions [13]. Starting from microcracks in the area of the highest material stresses below the surface, 
further cyclic loading lead to surface chipping (pittings) [30]. In order to calculate the fatigue lifetime of the hybrid bearing bushing, a simulation model has been set up. It combines a finite element analysis (FEA) of the component and a following fatigue life calculation. The basic procedure has already been extensively validated [33] and the approach for the fatigue life calculation is standardized in [34].

The FEA is based on a model of the hybrid bearing bushing, and the inner ring and rolling elements of a conventional type 7306 angular contact ball bearing with contact angle of $40^{\circ}$. It is derived from the geometry data of the previous simulations and was modified under consideration of subsequent machining steps. The FEA is developed in Ansys Mechanical APDL. The symmetry of geometry allows reducing the model to a sectional piece of $36^{\circ}$ with rotationally symmetric boundary conditions. Due to different meshing requirements for the fatigue life simulation, the mesh of the previous simulation step was not adopted. For the 3D modelling, an eight-node element (type SOLID185) was used. It utilizes the selective reduced integration method. Shear locking modes were neglected. All the supporting volumes, which were not relevant for the determination of the fatigue life, were free meshed with tetrahedral element geometry. The material zone subjected to rolling contact stress, was discretized using a mapped mesh and an element size of approximate $30 \mu \mathrm{m} \times 20 \mu \mathrm{m} \times 20 \mu \mathrm{m}$. The contact pair was set up as a flexible-flexible contact between the rolling element and the inner/outer ring. The elasticities were adjusted in accordance with the different materials. In addition, the contact pair was defined as a surface-surface contact. The contact elements were located on the contact surface of the rolling element, which had four nodes without middle node (type CONTA173). For the target surface of the bearing bushing and the inner ring, type TARGE170 was chosen, which had three nodes without middle node. The augmented Lagrange method was used to solve the nonlinear contact problem.

An external load can be induced as a radial force $F_{\text {rad }}$ and/or axial force $F_{\mathrm{ax}}$ on the inner ring segment (see Fig. 8a). Additional input variables are the geometry of the contact, the steel thickness and local material properties like residual stresses. To discretise the fine-meshed surface contact, the bearing bushings contact region was regularly meshed with eight-node elements. One solution of the FE model is the locally resolved orthogonal shear stress field $\tau_{\mathrm{O}}$ of all contact partners (Fig. 8b), which is required to calculate the fatigue life based on an approach by Ioannides, Berling and Gabelli [31]:

$\ln \left(\frac{1}{\mathrm{~S}}\right) \approx \mathrm{N}^{\mathrm{e}} \int_{\mathrm{V}} \frac{\left(\tau_{\mathrm{i}}-\tau_{\mathrm{u}}\right)^{\mathrm{c}}}{z^{\prime \mathrm{h}}} \mathrm{dV}$.

This allows calculating the probability of survival $S$ of the hybrid bearing bushing in dependence of the number

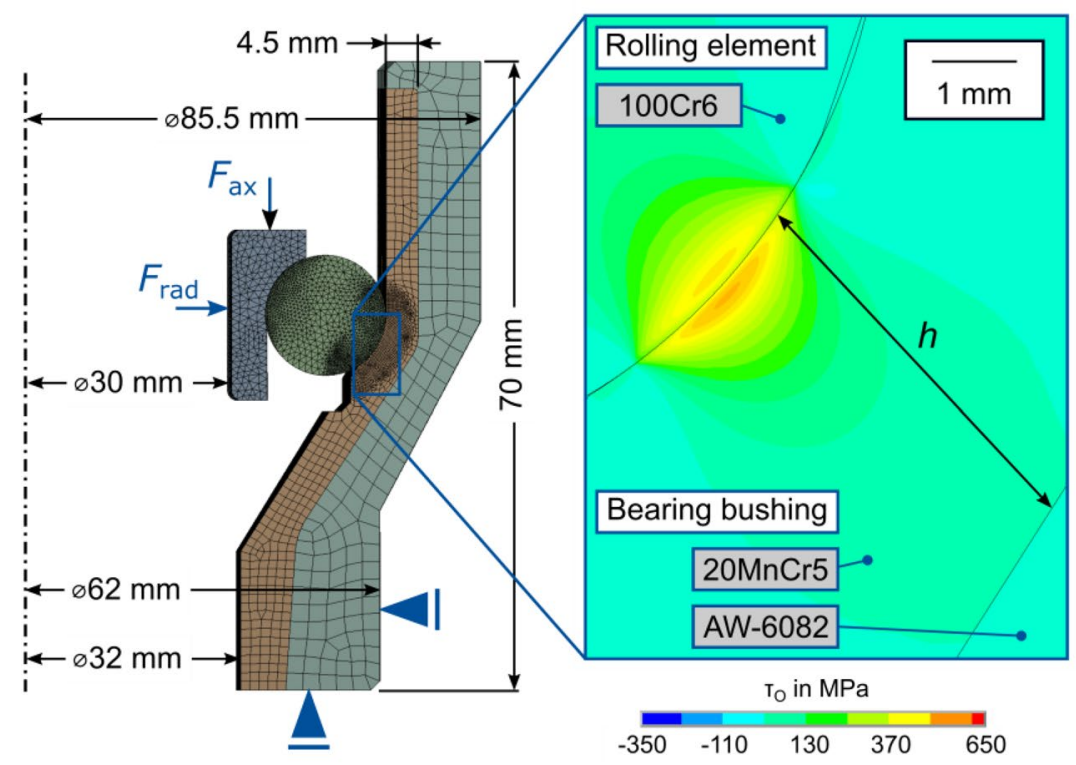

(a) (b)

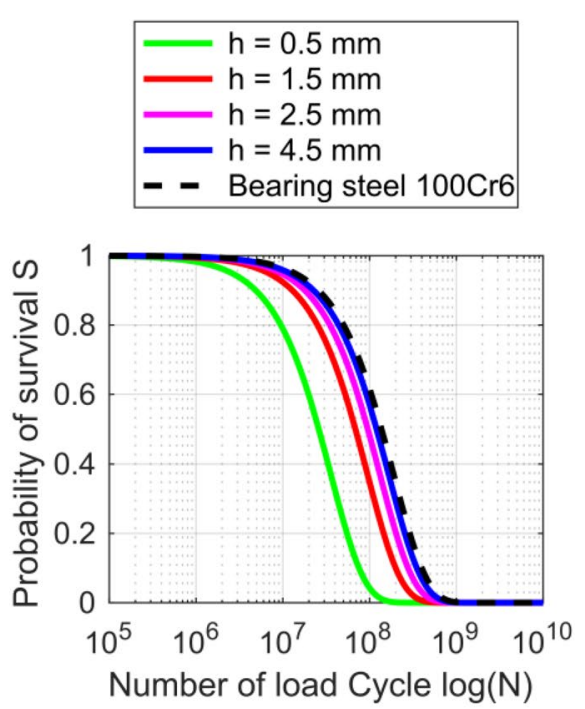

(c)
Fig. 8 Numerical investigations on fatigue life: a boundary conditions and meshed $\mathrm{FE}$ model for a $20 \mathrm{MnCr} 5$ steel thickness in the contact zone of $h=4.5 \mathrm{~mm}$; b orthogonal shear stress $\tau_{O}$ in the con- tact zone and marking for steel thickness; c calculated fatigue life for $F_{\text {ax }}=8875 \mathrm{~N} ; \mathrm{F}_{\text {rad }}=0$ for varying steel thicknesses 
of load cycles $N$, which the material volume $V$ has experienced. Besides a statistical parameter set $\left(e, c, z^{\prime}, h\right)$, a material dependent stress fatigue limit $\tau_{u}$ is used. This value is correlated with a fatigue stress criterion $\tau_{\mathrm{i}}$ after Dang Van, which states a linear relationship between hydrostatic pressure $p_{\text {hyd }}$ and maximum shear stress amplitude $\tau_{\mathrm{a}}$ [32]. The algorithm was set up in Matlab, so that the stress values from the simulation will be imported to calculate the fatigue life of the bearing bushing.

Numerical results for pure axial loading with $F_{\mathrm{ax}}=8875 \mathrm{~N}$ (medium to high load for the conventional bearing) and a steel thickness of $h=4.5 \mathrm{~mm}$ (derived from the previous simulation steps), provides a maximum orthogonal sheer stress of $\tau_{\text {o,max }}=523 \mathrm{MPa}$. It is located in a depth of $0.15 \mathrm{~mm}$ below the contact surface between rolling element and bearing bushing. In this characteristic depth, bearing damage through crack formation occurs. The crack progression increases with further load cycles and bearing failure is eminent when the crack exits the bushings surface and a pitting occurs. The calculated bearing fatigue life after Eq. (3) with a $90 \%$ likelihood of survival is $L_{10}=22.5 \times 10^{6}$ cycles (see Fig. 8c). It is evident, that the stress field extents to a depth of $4 \mathrm{~mm}$ with a value of around $130 \mathrm{MPa}$ (cf. Fig. 8b). Hence, the stress maximum resulting from the point contact is located in the hardened area, which was examined in the previous chapter. A thin steel layer $(h<0.5 \mathrm{~mm})$ would not be sufficiently dimensioned for the load parameters considered and would reduce the theoretical fatigue life by a factor of 4.7 to $L_{10} *=4.8 \times 10^{6}$ cycles. Here a local overload of the aluminium leads to structural failure of the entire component. However, the equivalent stress from a greater depth of $\mathrm{h}>3 \mathrm{~mm}$ below the surface of the contact point is low enough to apply the lighter aluminium base material. Further investigations can be found in [16, 17]. These theoretical findings will be verified by future fatigue bench tests. Further optimisation potential is seen in the dimensioning of a fatigue-resistant steel layer in accordance with application requirements. For this purpose, the fatigue behaviour of the joining zone and the intermetallic phase layer will be investigated in more detail in the future course of the project through the inclusion of local microstructural simulations.

\section{Summary and conclusions}

Based on the results presented in this study, the following conclusions can be drawn:

- The different steps of the novel tailored forming process chain were successfully modelled numerically and findings, suitable process parameters as well as possible problems for the experimental realisation of the single process steps were derived. The obtained results were considered for the simulation of the following process steps.

- The co-extrusion of aluminium-steel compounds was numerically investigated. The comparison between experimental and numerical investigations showed a high correlation. A phenomenological macroscopic model is implemented in the commercial FE code to determine the resulting intermetallic phase thicknesses which can be formed at relevant temperatures, times and contact pressures.

- Two induction-heating concepts with an inner induction coil were developed with the aid of numerical simulation in order to heat the materials to their material-specific forming temperatures. After induction heating and the subsequent transport time, it was possible to achieve a temperature gradient between steel and aluminium so that the both materials can be successfully formed to the final geometry. A sufficient inhomogeneous heating of aluminium and steel is thus possible in principle, but the rapid temperature equalisation during the transport time must be taken into account in the experimental implementation.

- For the design of the die forging process, the joined semifinished products were initially modelled in a simplified approach without considering the joining zone. Thus, a material flow calculation and tool analysis could be carried out for the bearing bushing in order to design the process and tools for the experimental investigations.

- For the prediction of damage and fatigue of the joining zone, a physically motivated crystal plasticity model is developed using the efficient virtual element method at microscale. This allows to account for microscopic fields for describing suitable mechanisms towards the physics within a microscopic joining zone of a bearing bush.

- The effective material behaviour of the microscopic material model was implemented in a macroscopic element formulation by using homogenization strategies.

- Prior to bearing fatigue tests a FEM model was set up and a calculational approach was applied allowing to investigate the desired material thickness of the handed and high strength surface zones.

- It has to be guaranteed that the orthogonal shear stresses due to the tribological contact lay within the hardened high strength material and that the steel layer is thick enough to avoid plastic deformations of the raceway.

- The operating behaviour of the hybrid bearing bushing was investigated by means of a theoretical fatigue life evaluation. The fatigue life calculated in this way is in the range of fatigue. The steel-aluminium thickness ratio is to be evaluated as sufficient.

In future investigations, a complete implementation and validation of all models in the corresponding software tools 
as well as the transfer of all result data to the next process step will be further examined in order to guarantee a fast and efficient simulation of the process chain. This should enable a scale-independent transfer of the individual findings to other processes as well as the derivation of further ideas for the improvement of tailored forming components through systematic analyses with the FE systems.

Acknowledgements The results presented were obtained in the subprojects A1, A2, B2, B3, C1, C3 and C4 of the Collaborative Research Centre 1153 "Process chain to produce hybrid high performance components by Tailored Forming"-252662854. The authors thank the Deutsche Forschungsgemeinschaft (German Research Foundation, DFG) for their financial support.

Funding Open Access funding enabled and organized by Projekt DEAL.

Open Access This article is licensed under a Creative Commons Attribution 4.0 International License, which permits use, sharing, adaptation, distribution and reproduction in any medium or format, as long as you give appropriate credit to the original author(s) and the source, provide a link to the Creative Commons licence, and indicate if changes were made. The images or other third party material in this article are included in the article's Creative Commons licence, unless indicated otherwise in a credit line to the material. If material is not included in the article's Creative Commons licence and your intended use is not permitted by statutory regulation or exceeds the permitted use, you will need to obtain permission directly from the copyright holder. To view a copy of this licence, visit http://creativecommons.org/licenses/by/4.0/.

\section{References}

1. Duan X, Velay X, Sheppard T (2004) Application of finite element method in the hot extrusion of aluminium alloys. Mater Sci Eng 369(1-2):66-75. https://doi.org/10.1016/j. msea.2003.10.275

2. Schwane M, Citrea T, Dahnke C, Haase M, Ben Khalifa N, Tekkaya AE (2014) Simulation of composite hot extrusion with high reinforcing volumes. Proc Eng 81:1265-1270

3. Neugebauer R, Glaß R, Popp M, Porstmann S, Kittner K (2011) Indirect extrusion of semi-finished aluminium-magnesium compounds. Mat.wiss. u Werkstoff 42(7):585-592. https://doi. org/10.1002/mawe.201100822

4. Kittner K (2012) An integrative approach for co-extrusion of aluminum-magnesium-compounds. Berichte aus der Virtuellen Fertigungstechnik 9. Dissertation, Technische Universität Chemnitz

5. Misirli C, Cetintav I, Can Y (2016) Experimental and fem study of open die forging for bimetallic cylindrical parts produced using different materials. Int J Modern Manuf Technol 8(1):69-74

6. Politis DJ, Lin J, Dean TA (2012) Investigation of material flow in forging metal components. In: Proceeding of the 14th international conference on metal forming. pp 231-234

7. Wang J, Langlois RM, Bigot R, Lu H (2014) Study of the hot forging of weld cladded work pieces using upsetting tests. J Mater Process Technol 214(2):365-379

8. Lemaitre J (2012) A course on damage mechanics. Springer Science \& Business Media, Berlin
9. Miehe C, Mauthe S, Hildebrand FE (2014) Variational gradient plasticity at finite strains. Part III: local-global updates and regularization techniques in multiplicative plasticity for single crystals. Comput Methods Appl Mech Eng 268:735-762

10. Wriggers P, Aldakheel F, Hudobivnik B (2019) Application of the virtual element method in mechanics. GAMM-Rundbriefe 01(2019):4-10

11. Tong D, Gu J, Yang F (2018) Numerical simulation on induction heat treatment process of a shaft part: involving induction hardening and tempering. J Mater Process Technol 262:277-289. https://doi.org/10.1016/j.jmatprotec.2018.06.043

12. Herbst S, Maier HJ, Nürnberger F (2018) Strategies for the heat treatment of steel-aluminium hybrid components. HTM J Heat Treat Mater 73(5):268-282. https://doi.org/10.3139/105.11036

13. Sadeghi F, Jalalahmadi B, Slack TS, Raje N, Arakere NK (2009) A review of rolling contact fatigue. ASME J Tribol 131(4):041403. https://doi.org/10.1115/1.3209132

14. Hetzner DW (1998) Laser glazed bearings. In: Hoo JJC (ed) Bearing steels: into the 21 st century, 1327th edn. American Society for Testing and Materials, ASTM International, West Conshohocken

15. Ringsberg JW, Skyttebol A, Josefson BL (2005) Investigation of the rolling contact fatigue resistance of laser cladded twindisc specimens: FE simulation of laser cladding, grinding and a twin-disc test. Int J Fatigue 27:702-714

16. Coors T, Pape F, Poll G (2019) Theoretical investigations on the fatigue behavior of a tailored forming steel-aluminium bearing component. AIP Conf Proc 2113:40020. https://doi. org/10.1063/1.5112554

17. Hwang JI, Coors T, Pape F, Poll G (2020) Simulation of a steelaluminium composite material subjected to Rolling Contact Fatigue. Lubricants 7(12):109. https://doi.org/10.3390/lubri cants7120109

18. Behrens B-A, Klose C, Chugreev A, Heimes N, Thürer SE, Uhe J (2018) A numerical study on co-extrusion to produce coaxial aluminum-steel compounds with longitudinal weld seams. Metals 8:717. https://doi.org/10.3390/met8090717

19. Chanda T, Zhou J, Kowalski L, Duszzyk J (1999) 3D FEM simulation of thermal events during AA6061 aluminium extrusion. Scripta Mater 41(2):195-202

20. Behrens B-A, Klose C, Thürer SE, Heimes N, Uhe J (2019) Numerical modeling of the development of intermetallic layers between aluminium and steel during co-extrusion. AIP Conf Proc 2113:040029. https://doi.org/10.1063/1.5112563

21. Abrikosov AA (1988) Fundamentals of the theory of metals, vol 1. North-Holland, Amsterdam

22. Behrens B-A, Bouguecha A, Vucetic M, Huskic A, Uhe J, Frischkorn C, Matthias T, Stakhieva A, Duran D, Thürer SE, Golovko O, Klose C (2016) Umformtechnische Herstellung hybrider Lagerbuchsen. wt Werkstattstechnik online 106(10):743-748

23. Saunders N, Guo UKZ, Li X, Miodownik AP, Schillé J-P (2003) Using JMatPro to model materials properties and behaviour. JOM 55(12):60-65. https://doi.org/10.1007/s11837-003-0013-2

24. Henning F, Moeller E (2011) Handbuch Leichtbau: Methoden, Werkstoffe, Fertigung. Hanser, München

25. Roters F, Eisenlohr P, Hantcherli L, Tjahjanto D, Bieler T, Raabe D (2010) Overview of constitutive laws, kinematics, homogenization and multiscale methods in crystal plasticity finite-element modeling, Theory, experiments, applications. Acta Mater 58(4):1152-1211. https://doi.org/10.1016/j.actam at.2009.10.058

26. Stein E, de Borst R, Hughes TJR (2004) Encyclopedia of computational mechanics, volume 2: solids and structures. Wiley, Chichester 
27. Nacke B (1987) Ein Verfahren zur numerischen Simulation induktiver Erwärmungsprozesse und dessen technische Anwendung. Dissertation, Leibniz Universität Hannover

28. Rudajevová A, Buriánek J (2001) Determination of thermal diffusivity and thermal conductivity of $\mathrm{Fe}-\mathrm{Al}$ alloys in the concentration range 22 to 50 at.\% Al. J Phase Equilib 22(5):560-563. https://doi.org/10.1007/s11669-001-0075-1

29. Herbst S, Aengeneyndt H, Maier HJ, Nürnberger F (2017) Microstructure and mechanical properties of friction welded steel-aluminum hybrid components after T6 heat treatment. Mater Sci Eng 696:33-41. https://doi.org/10.1016/j. msea.2017.04.052

30. Voskamp A (1996) Microstructural changes during rolling contact fatigue-metal fatigue in the subsurface region of deep groove ball bearing inner rings. Phd. Thesis, TU Delft

31. Ioannides E, Berling G, Gabelli A (1999) An analytical formulation for the life of rolling bearings. Mechanical Engineering 137, Espoo, Acta Polytechnica Scandinavica
32. Dang Van K (1973) Sur la résistance à la fatigue des métaux. Sciences Techniques Armement 47 Imprimerie Nationale, Paris

33. Neubauer T (2016): Betriebs- und Lebensdauerverhalten hartgedrehter und festgewalzter Zylinderrollenlager (in german), $\mathrm{PhD}$ Thesis, Leibniz University Hannover

34. International Organization for Standardization (2007) Rolling bearings - dynamic load ratings and rating life (ISO Standard No. 281). https://www.iso.org/standard/38102.html. Accessed 3 Feb 2020

Publisher's Note Springer Nature remains neutral with regard to jurisdictional claims in published maps and institutional affiliations. 